\title{
O que assusta em Paulo Freire: educação libertadora na América Latina hoje
}

\author{
Cândida Beatriz Alves* \\ Regina Lúcia Sucupira Pedroza**
}

\section{Resumo}

A partir da análise de cartaz contrário a Paulo Freire em manifestação pró-impeachment da então presidenta do Brasil Dilma Roussef, o artigo se propõe a explicitar que o rechaço a esse educador e a sua proposta pedagógica, que aparenta ser novo, é, de fato, apenas uma nova roupagem para questões antigas na América Latina, explicitadas pelos estudos decoloniais na região. Obras como a de Paulo Freire mostram-se revolucionárias ao propor uma educação popular que visa a transformação social. Trata-se não de uma técnica, mas de uma postura de respeito, solidariedade e reconhecimento no outro daquilo que não sabemos. O movimento Escola sem Partido, que pretende acabar com uma suposta doutrinação de esquerda nas escolas, vigiando o professor, tem Paulo Freire como alvo preferencial. Aborda-se, neste trabalho, o caráter ideológico e reforçador do status quo que tal proposta defende.

Palavras chave

América Latina, estudos decoloniais, Paulo Freire, educação.

Recepció original: 21 de março de 2021

Acceptació: 2 de maig de 2021

Publicació: 1 de juliol de 2021

Em março de 2015, em manifestação que pedia o impeachment da então presidenta do Brasil Dilma Rousseff, uma faixa, que viria a ficar famosa, trazia a seguinte reivindicação: «Chega de doutrinação marxista. Basta de Paulo Freire». Empunhada por professores do Instituto Federal de Brasília -instituição criada no governo do colega de partido de Dilma, o presidente mais popular que o Brasil já tivera, Luís Inácio Lula da Silva-, a frase inundou os noticiários brasileiros por semanas, talvez em razão da surpresa que ela causara a alguns, talvez em razão do anúncio de tempos sombrios que ela carregava.

Paulo Freire, considerado o patrono da educação brasileira, pedagogo respeitado e estudado mundo afora, estava sendo, sem rodeios, convidado a se retirar de cena, junto com a primeira mulher a ocupar o cargo de chefe do Executivo do país latinoamericano. A frase, que pareceu em um primeiro momento algo inusitado, quase descabido, logo mostrou que vinha para ficar, com respaldo de poderosos -atores políticos conservadores, do setor empresarial e da mídia-, fazendo ecoar um grito seco da garganta de parte da população, amedrontada pela espetacularizada volta do comunismo.

Importantes acontecimentos políticos se seguiram e o rechaço a Paulo Freire e a sua obra se tornaram crescentes, juntamente com o recrudescimento de uma onda conservadora encabeçada pela extrema direita em um país que havia sido governado por 14 anos pelo Partido dos Trabalhadores. No âmbito da educação, as demandas desse

${ }^{*}$ ) Professora do Instituto Federal de Brasília (IFB). Correio eletrônico: candida.alves@gmail.com

${ }^{* *}$ Professora da Universidade de Brasília. Correio eletrônico: rpedroza@unb.br 
movimento foram centralizadas pelo grupo autointitulado Escola Sem Partido (ESP), que, fundado em 2004, se imbuiu do objetivo de lutar «pela descontaminação e desmonopolização política e ideológica das escolas» ${ }^{1}$.

Neste artigo, pretendemos explicitar que o rechaço a Paulo Freire e a sua proposta pedagógica, que aparenta ser novo, é, de fato, apenas uma nova roupagem para questões antigas no mundo - sobretudo na América Latina. Defensor da aproximação do Brasil a seus vizinhos latino-americanos, contra a postura imperialista vinda dos EUA, esse autor é posto de lado no momento em que o país norte-americano volta a ser exaltado como principal parceiro político do Brasil no cenário internacional.

É, portanto, pelo viés do colonialismo que tentaremos aqui entender a velha nova rejeição a Paulo Freire simbolizada pela frase apresentada no início deste texto. Além disso, obras como a de Freire mostram-se particularmente revolucionárias ao propor uma educação popular que visa à transformação do status quo. Trata-se não de uma mera técnica de alfabetização -como muitas vezes é visto-, mas de um estar no mundo que pressupõe uma postura de respeito, solidariedade e reconhecimento no outro daquilo que não sabemos. O saber popular é alçado ao nível de conhecimento, o que entra em choque com a colonização do ser e das mentalidades, própria à ação colonizadora.

\section{Brasil, um país fora da Latinoamérica}

A relação entre os países da América Latina é marcada por aproximações e distanciamentos, o que pode ser entendido historicamente a partir de questões internas em constante interação com questões externas a essa região, particularmente no que diz respeito à relação estabelecida com os EUA e a Europa. A relação entre essas regiões tem sido marcada por uma subordinação de ordem colonialista que se manifesta nas dimensões econômica, política, cultural e subjetiva. A postura do Brasil de virar as costas para o restante da América Latina é algo que deve, portanto, ser entendido histórica e politicamente.

A América Latina se conformou a partir do lugar da alteridade: exotismo e mistério marcados pelo ponto de vista dos colonizadores europeus, que viam no novo continente uma oportunidade comercial. O domínio colonial marca de tal forma o surgimento do novo continente, que se expressa inclusive na nomenclatura pela qual ele é conhecido: América Latina, sendo o latino vinculado à tradição europeia. Nessa narrativa de origem, não há espaço para outros povos -como povos nativos ou africanos- estando todos submetidos à narrativa colonial dominante (Ardao, 1980).

Apesar de a América do Norte ter ficado, por razões históricas, assim conhecida, a América Latina deve ser entendida como a antítese dessa, uma vez que aquela representaria a América Saxã, a legítima herdeira do Velho Mundo no continente do outro lado do Atlântico (Ardao, 1980). A relação colonial estabelecida com a metrópole logo se espelharia, portanto, na relação entre América Latina e o principal representante da América Saxã, os EUA.

(1) Recuperado de https://www.escolasempartido.org/ [acceso 02/04/2021]. 
Por outro lado, pode-se dizer que a unidade de sentido que se forma a partir da colonização é também o que unifica povos tão diferentes entre si como aqueles que habitavam e habitam a América Latina (Tavolaro, 2009). De fato, essa nomenclatura vem sendo historicamente questionada, afinal como poderia uma única designação abarcar tantas línguas, culturas e experiências? Além disso, como não questionar uma ideia de América Latina diretamente concebida pela colonização? (Dussel, 1994; Mignolo, 2005).

É a partir da compreensão do lugar que a América Latina ocupa na Modernidade que se deve compreender a persistência do nome - tanto no senso comum quanto no ambiente acadêmico, que tanto o questiona. Assim, apesar de designar realidades sociais, históricas e culturais tão diversas, a América Latina continua se unindo como o avesso da Modernidade. Se Europa e EUA -este último como herdeiro autorizado do primeiro- seriam os representantes legítimos da Modernidade, a América Latina seria reconhecida pelos distintivos de sua antimodernidade. Seriam, portanto, aqueles países colonizados sobretudo por ibéricos -apesar da presença das mais variadas nacionalidades europeias na região, inclusive franceses e ingleses-, mestiços, que fazem conviver uma natureza exuberante com a sua incapacidade política, cultural e intelectual. Estariam, assim, marcados inelutavelmente pelo subdesenvolvimento e pelo atraso econômico e moral (Tavolaro, 2009; Escobar, 2007).

Segundo Dussel (1994), importante autor da perspectiva decolonial latinoamericana, haveria um mito da Modernidade que teria embasado a colonização e perduraria até a atualidade, segundo o qual a Europa, por sua superioridade, estaria a tal ponto moralmente obrigada a trazer o desenvolvimento ao bárbaro inferior, que isso justificaria até mesmo o uso da violência contra quem se opusesse ao processo civilizatório. A violência seria, portanto, um mal necessário, uma vez que caberia aos superiores tutelarem os atrasados. Nesse sentido, a Modernidade seria sempre vista em seu lugar de neutralidade e inevitabilidade; inocente, portanto, diante de qualquer sofrimento imposto aos bárbaros, esses sim culpados por sua barbaridade.

Dessa forma, a América Latina e a colonização aqui conduzida representariam o duplo caráter da Modernidade: internamente (à Europa), ela seria o triunfo da racionalidade humana; externamente, ela explicitaria um máximo de irracionalidade, materializada na forma de violência ao outro indígena e africano. O conteúdo mítico sustentado internamente justificaria o extermínio levado a cabo externamente (Dussel, 2000).

Não só um genocídio, contudo, teria tido lugar na América Latina, mas também um epistemicídio, na medida em que também os saberes desses povos teriam sido alvo de extermínio (Santos, 2007). Ignorantes, primitivos e supersticiosos seriam as pechas agora atribuídas aos povos não brancos, que passam a constituir a negação do sujeito moderno, sua completa exterioridade. Tais rótulos, internalizados como verdadeiros $-\mathrm{a}$ partir de uma mitologia do eurocentrismo-, causam impacto também sobre as dimensões psíquica e identitária desses sujeitos, que passam a se constituir subjetivamente a partir da crença na superioridade da civilização branca. Essa condição levou a que valores associados à civilização branca fossem desejados, ao passo que os próprios valores tradicionais seriam rechaçados (Mignolo, 2000).

Por outro lado, a unificação da América Latina sob a égide da falta e do atraso, também levou a uma crescente vontade política de diferenciação tanto das antigas metrópoles europeias quanto da América de colonização inglesa. Isso se traduziu, para citar um exemplo simbólico, no rechaço à doutrina Monroe de 1823, que defendia a 
união de toda a América sob controle estadunidense, bem como em vários outros eventos históricos que buscavam afirmar a independência da América Latina perante o jugo colonial. Também no âmbito acadêmico, intelectuais tiveram e têm importante papel na crítica ao discurso colonialista (Dussel, 1994; Castro-Gómez, 2000; Quijano, 2000; Mignolo, 2005)

Apesar de se unir aos países latino-americanos de matriz hispânica em função da pecha de atrasado e subdesenvolvido, o Brasil por outro lado se destaca deles em função da colonização lusitana que sofreu. Assim, pode-se falar de convergências significativas que unem o Brasil aos demais Estados latino-americanos, mas não se pode negar que há importantes divergências de um ponto de vista histórico, cultural, linguístico e político. É importante, de qualquer forma, destacar, que tanto semelhanças quanto diferenças não são dadas a priori, sendo antes construções históricas e políticas. Até mesmo a diferença da língua deve ser encarada como uma construção histórica, uma vez que outros exemplos demonstram que o bilinguismo não tem representado um obstáculo à integração em outras partes do mundo (Anderson, 2008).

Para explicitarmos algumas semelhanças, podemos mencionar o modelo similar de colonização, levado a cabo por países da península ibérica, voltado para a exploração predatória. A formação da sociedade se estruturou, portanto, com base em uma elite vinda da Europa e uma grande massa de mão de obra formada por negros e indígenas, o que marcou a existência de fortes disparidades sociais (Dongui, 1975).

Por outro lado, diferenças se fazem notar, por exemplo, na presença monárquica vivenciada pela experiência brasileira, única no contexto latino-americano. O Brasil se gabava dessa proximidade com a família real portuguesa, o que o diferenciaria das demais nações latino-americanas, taxadas de repúblicas caudilhistas e instáveis (Fausto, 2008). Outra diferença era a quantidade de negros escravizados na ex-colônia portuguesa, ao passo que os vizinhos latino-americanos contavam com uma população sobretudo indígena e branca. Tal diferença, se significativa em termos culturais e étnicos, punha o Brasil igualmente no lugar de país de mestiços, em que brancos eram vilipendiados por sua mistura com raças degradadas.

Conduzida pelas mãos da elite e de intelectuais, a constituição de uma identidade nacional nos países latino-americanos foi, em grande medida, espelhada no outro europeu e estadunidense, que se tentava mimetizar. Buscava-se alcançar a difícil tarefa de figurar como nação civilizada no cenário internacional. No processo de formação cultural desses países, Europa e EUA eram, portanto, as referências constantes, o que punha em segundo plano -um plano inclusive mal-visto- a relação entre vizinhos de continente (Madeira e Veloso, 1999). O percurso histórico latino-americano, principalmente quando se trata da relação do Brasil com os demais países, é marcado por distanciamentos e aproximações, convergências e divergências, tendo como grandes outros os EUA e a Europa, referências de Modernidade.

\section{Ser latino-americano: construção, educação e resistência}

A pergunta sobre a identidade latino-americana tem persistido ao longo do tempo existem escritos desde o século xviii sobre o ser latino-americano (Ardao, 1980)- e o que é mais intrigante sobre ela não são as possíveis respostas, mas a frequência com que tem sido feita ao longo dos últimos séculos (Díaz-Genis, 2004). O questionamento «O que significa ser latino-americano? (...) está mudando enquanto se constroem novas 
respostas. Nesse debate, continua havendo vozes históricas, mas a elas vêm se somar outras diferentes, às vezes com novos argumentos» (Canclini, 2008, p. 12).

O sujeito latino-americano, ao tentar se afastar do seu passado de colonização, se aproximando do ideal ocidental -inicialmente europeu e posteriormente estadunidense-, apenas reforçou seu lugar de colonizado. Assim, além de cópias imperfeitas das metrópoles, os latino-americanos seguiam em uma relação de dependência econômica, política, cultural e subjetiva com essas (Zea, 1976).

É nesse contexto que as Ciências Humanas se consolidam, tendo um molde tácito para o humano, em referência ao qual todos homens e mulheres seriam medidos e julgados. O homem branco, europeu e cristão seria então o parâmetro de civilização, ao passo que, do outro lado do espectro da racionalidade, estariam os povos não brancos, não cristãos e não europeus, habitantes da África, da Ásia e da América Latina, sobre os quais aquele modelo de civilidade não só poderia como deveria ser imposto (CastroGómez, 2000).

A oposição entre civilização e barbárie -título do célebre livro de Domingos Sarmiento de 1845- foi recorrente no pensamento latino-americano, no qual a barbárie era associada a si próprio e a civilização se impunha como o ideal que vinha de alhures. No mesmo sentido, alusões à peça shakespeariana A Tempestade (Retamar, 1971; DíazGenis, 2004; Rodó, 2006) associavam o latino-americano a Caliban, o canibal ignorante, e o europeu civilizador a Próspero, o desbravador que escraviza Caliban.

Dessa forma, se, por um lado, pode-se dizer que o ser latino-americano é formado por distintas alteridades que se imiscuem em uma construção histórica, por outro, não se pode negar o que há em comum, como afirma Martin-Baró:

Cada país tem suas peculiaridades e seus recursos, sua história e seus problemas. Contudo, tampouco se pode ignorar o que há de comum entre os povos latinoamericanos. A América Latina é, sob muitos aspectos, algo mais que um nome (...). Essa generalidade latino-americana assenta-se em raízes étnicas, sociais e culturais muito profundas, mas é, acima de tudo, um horizonte, ou melhor dito, uma tarefa histórica para os povos desses países. (Martin-Baró, 2009, p. 206)

É nesse sentido que a afirmação do ser latino-americano envolve também uma reconstrução deste, a partir de um posicionamento crítico diante de sua constituição no âmbito da colonialidade cultural, histórica e subjetiva. Nessa empreitada, a educação cumpre uma função primordial, desde que esta se faça valer como uma educação dialógica e libertadora.

Alguns movimentos e personalidades históricas na área de educação tem procurado agir nesse sentido. Antes de falar desse que é o foco do presente artigo, uma vez que é o citado na faixa anunciada em nossa introdução, bem como alvo preferencial do movimento ESP -Paulo Freire-, falaremos de outra figura essencial para a conformação de uma educação popular e emancipadora na América Latina. Trata-se de Simón Rodríguez, educador e filósofo venezuelano nascido na segunda metade do século xviii e conhecido por ter sido o mais influente professor de Simon Bolívar, figura que tanto fez pela unidade da América Latina. Entretanto, como alerta Kohan (2015), reduzir Simón Rodríguez a sua ligação com Bolívar é extremamente limitado diante do que foi sua vida e obra.

Rodríguez foi, acima de tudo, duas coisas: um viajante e um educador. Percorreu vários países da América Latina assim como da Europa. Em suas andanças, sempre se 
envolvia com a educação, construindo escolas, atuando como professor e se ocupando com questões políticas concernentes à educação. Era ferrenho defensor da escola para todos. Para ele, se uma pessoa estivesse fora da escola, a escola estava fracassando. E essa escola deveria não só abarcar a todos como abarcar a todos de forma igualitária, respeitando sua cultura, sua língua, seu conhecimento, sua tradição. Nas escolas que fundou, conviviam o espanhol, o quéchua e qualquer outro idioma falado por algum estudante. O saber desse deveria ser valorizado, sempre, e ao professor caberia a tarefa de se colocar também como ouvinte e aprendiz desse aluno (Kohan, 2015).

Um ponto muito marcante nas ideias de Rodríguez era o seu convite à invenção e à criatividade: o educador se posicionava veementemente contra qualquer forma de cópia e imitação de ideias. Para ele, a verdadeira educação era aquela que ensinava o aluno a perguntar, a questionar e nunca se satisfazer com aquilo que estava dado, mas ousar. Por meio do livre pensar, poder-se-ia chegar ao novo, aquilo que verdadeiramente responderia às demandas e necessidades daquela realidade, que era única.

É nesse sentido que Rodríguez se posiciona, também, a favor de uma educação original na América -não usa o termo América Latina, ainda pouco disseminado à época (Ardao, 1980)-, uma educação que valorizasse os saberes locais e que não tentasse se constituir como cópia mal-acabada do que era feito alhures. Mostrava, assim, uma postura de combate ao que viria a ser chamado mais tarde por autores decoloniais de «colonialidade do ser» (Quijano, 2000). Dessa forma, a postura do professor deveria ser não a de transmissor de um conteúdo pronto e acabado -o que Rodríguez chama de professores buzinas- mas favorecer o pensamento e a criatividade do educando. $\mathrm{O}$ educador criticava, portanto, o ensino que via sendo ofertado, pois ele se caracterizava pela falta de espaço para questionamentos e reflexão, fazendo os alunos repetirem como papagaios silogismos que apenas serviam para reforçar a situação de opressão e desigualdade social que havia naqueles países.

Desse modo, é um pensamento que apresenta claras semelhanças com o de Paulo Freire, conforme veremos na sequência. Sobretudo o compromisso com os excluídos, a valorização da reflexão crítica e a defesa de uma educação latino-americana original, criativa e popular são distintivos de ambos os autores, que mostram como há, na região, um esforço histórico pela constituição de um ser latino-americano autônomo e reflexivo. Claramente não é uma tarefa fácil, como atestam a vida tanto de Rodríguez quanto a de Freire. O primeiro, apesar de ter chegado a ser ministro da educação de Bolívar na Bolívia, passou por agudas dificuldades financeiras e foi frequentemente taxado de louco. O segundo, apesar do reconhecimento em vida, foi preso e forçado a exilar-se. Além disso, anos depois de sua morte, torna-se alvo de uma grande campanha de linchamento de sua obra, conforme detalharemos a seguir.

\section{Paulo Freire, um educador latino-americano}

O olhar sobre a América Latina marca a trajetória de Paulo Freire. Forçado a imigrar durante a Ditadura Militar (1964-1984), uma vez que já era figura proeminente à época -havia sido o responsável pelo plano nacional de alfabetização do governo de João Goulart, destituído pelos militares-, Freire busca exílio no Chile após 72 dias de prisão. Fica em território chileno por alguns anos, em seguida passa por países como Bolívia, Suíça, São Tomé e Príncipe, Guiné-Bissau, dentre outros, antes de retornar para o Brasil em 1980. 
Ao tratar da obra do autor, nos centraremos sobre o livro Pedagogia do Oprimido (2005), que tem como objetivo explicitar a relação oprimido-opressor em suas mais variadas vertentes, e justamente por isso guarda afinidades com o pensamento decolonial latino-americano. Além da base marxista, pode-se notar também a influência da Teologia da Libertação, que marca profundamente a obra de Paulo Freire. O pedagogo brasileiro estabelece também uma ponte clara com o pensamento de Frantz Fanon, fazendo por vezes uso da expressão «condenados da terra» em referência aos oprimidos (Penna, 2014).

Outra convergência são os pares metrópole-colônia e opressor-oprimido, que se relacionam a partir de uma perspectiva dialética, deveras presente tanto na obra freireana, quanto na literatura decolonial para dar conta dos processos de dominação política, econômica, cultural e subjetiva. Paulo Freire, ao desenhar sua dialética da opressão, traça uma analogia com a dialética do senhor e do escravo descrita por Hegel. Nesse sentido, a classe opressora e a oprimida encontram-se indissociavelmente ligadas e se constituem uma a outra, como polos opostos em uma relação de dependência: «ao fazer-se opressora, a realidade implica a existência dos que oprimem e dos que são oprimidos» (Freire, 2005, p. 41-42).

Paulo Freire (2005) empreende a análise dessa estrutura opressora que, para ele, é comum a toda a América Latina. Tanto ele quanto autores decolonialistas -como Dussel, Mignolo e Quijano- entendem que a opressão se viabiliza por um opressor que se mostra como um amigo que oferece ajuda, o que a torna ainda mais perversa. É assim que uma sociedade metropolitana invade e domina uma sociedade dependente e que uma classe domina outra, dentro de uma mesma sociedade. Soma-se a isso um processo de socialização e educação que se funda na internalização de características do opressor, processo, como vimos, nomeado por Quijano (2000) de «colonização do ser» e que poderíamos entender como análogo ao que Paulo Freire denomina por alienação do ser. O conteúdo que leva a essa alienação é o que Freire chama de mitologia da estrutura opressora, que possui grandes semelhanças com a mitologia do eurocentrismo que descrevemos acima (Dussel, 2000).

Dessa forma, a invasão cultural leva a uma inautenticidade do ser daqueles que são invadidos, revelando, portanto, a dimensão psíquica dessa conquista, condição sine qua non para o êxito da empreitada. É em razão da premência da estrutura opressora nos países colonizados que Freire, ao tratar do que chama de fatalismo dos oprimidos, afirma que isso se dá muito mais em razão de uma condição histórica das sociedades invadidas do que como «um traço essencial da forma de ser do povo» (Freire, 2005, p. 54). Assim, a invasão pode avançar tanto mais, quanto mais é introjetado um sentimento de inferioridade por parte dos invadidos, ou, poderíamos dizer, colonizados. Dessa forma, esses tendem a ser vistos e a se ver como seres incapazes e ignorantes. Na esteira dessa pecha, sua visão de mundo é desvalorizada, seu conhecimento, desqualificado e sua cultura, anulada - processos análogos ao epistemicídio e à colonização das mentalidades que discutimos acima (Santos, 2007; Quijano, 2000).

De acordo com Freire (2005), é, em grande medida, por meio de uma educação dita «bancária» que os mitos da classe opressora são transmitidos às classes oprimidas e que, portanto, todo o processo de alienação é reforçado e levado a cabo. O saber popular é, nesse cenário, desprezado e o saber científico só é válido na medida em que serve à manutenção do status quo. Essa educação se baseia na fragilidade de um espaço 
dialógico em que o mundo em que se vive e os temas que daí emergem possam ser abordados de forma crítica. Os conteúdos são inculcados como depósitos bancários fatos consumados, verdades absolutas- nas mentes dos aprendizes, que são colocados no lugar da ignorância e da passividade, manobra conseguida em vista da suposta autoridade do educador.

É assim que, em consonância com o que diz Althusser (1985), a escola se constitui como um dos aparelhos ideológicos do Estado, instrumento de transmissão da visão de mundo hegemônica, dominada por uma elite que se revela intrinsecamente como colonizada. É interessante destacar a presença do termo ideológico na expressão de Althusser, uma vez que esse será utilizado à exaustão pelos apoiadores do movimento ESP, conforme veremos na sequência, porém com outro sentido e propósito. Diferentemente do que dá a entender Althusser com o seu conceito, entretanto, Paulo Freire vê uma outra educação possível. Ao denunciar a educação bancária, o pedagogo brasileiro anuncia uma educação conscientizadora, emancipadora, que pretende romper com a relação estabelecida entre oprimido e opressor - essa relação de opressão que faz com que o primeiro se sinta inferior e deseje se tornar o último.

E é nesse sentido que essa educação se apresenta como ameaça. Explicitar a relação oprimido-opressor, a mitologia da estrutura opressora e a educação que busca a qualquer custo a perpetuação do status quo é ameaçador e precisa ser contido. As estratégias de contenção são tão mais perversas por estarem sendo conduzidas pelos próprios colonizados, que, alienados de seu ser, sonham em um dia se tornar metrópole. Ou, nos termos freireanos, os oprimidos que sonham em se tornar elite e classe dominante. $\hat{E}$ assim que veremos o discurso contrário a uma suposta doutrinação em curso nas escolas encher a boca dos mais humildes da população, que tanto teriam a se beneficiar de um ensino progressista, verdadeiramente libertador.

\section{Escola sem Partido em uma perspectiva decolonial}

Em entrevista concedida em julho de 2016 para um canal de televisão brasileiro (Canal Futura), Miguel Nagib, advogado fundador do Movimento Escola Sem Partido, acusou Paulo Freire de ser o pedagogo do Partido dos Trabalhadores, incumbido de alcançar os objetivos do partido no âmbito educacional, objetivos esses estreitamente relacionados com aqueles do comunismo. De acordo com Nagib, o professor não pode falar o que pensa em sala de aula, uma vez que isso fere a liberdade de consciência e de crença do aluno, bem como sua liberdade de aprender, assegurada pela Constituição Brasileira (Ramos e Santoro, 2017).

Na esteira desses pensamentos, o projeto ESP defende que o ensino no Brasil está contaminado por ideologias de esquerda, que fariam apologia, dentre outras coisas, ao socialismo e à assim chamada ideologia de gênero ${ }^{2}$, indo contra a religião cristã e os valores éticos da família. Nos termos usados pelos apoiadores do movimento, essa doutrinação estaria sendo feita por professores esquerdistas, que, formados em universidades promotoras de balbúrdia, estariam agitando mentes indefesas em prol de uma iminente revolução comunista (Ramos e Santoro, 2017).

(2) O termo ideologia de gênero vem sendo utilizado para se referir à compreensão de que os gêneros são constituídos social e culturalmente e não determinados pelo sexo biológico. 
Defende-se, assim, a ideia de que as mazelas da educação brasileira se explicam pela presença, em sala de aula, de um «exército de professores doutrinadores», que se aproveitam da audiência cativa dos estudantes para imprimir-lhes suas convicções ideológicas, bem como afrontar os valores morais e religiosos das famílias. Como um dos pontos centrais das discussões nesse âmbito, está a questão da neutralidade, que seria alcançada com o fim da doutrinação ideológica nas escolas ${ }^{3}$.

Cabe aqui uma reflexão sobre o sentido que o termo ideologia tem recebido. Seja como falsa consciência, como mentira, ou ainda como uma determinada compreensão do mundo baseada em significados construídos histórica e socialmente, todos esses sentidos são banidos. O que se defende é uma instrução tecnicista, um ensino destituído de qualquer ingerência subjetiva, política ou histórica. Essa seria a tão desejada neutralidade, almejada pelos apoiadores do ESP, que veem em Paulo Freire o principal alvo a ser atacado (Ramos e Santoro, 2017).

É interessante observar que o que o ESP considera um ensino neutro é justamente aquele que coincide com as características do pensamento colonizado. Ou seja, partese do ponto de vista do colonizador como sendo o parâmetro, o ponto de partida para julgar tudo aquilo que dele difere. Da mesma forma que o homem branco cristão heterossexual fez com indígenas e negros, considerando a si próprio o modelo ideal de ser humano, o ESP faz com a ideologia, considerando a sua o modelo de neutralidade a partir da qual as demais ideologias deverão ser julgadas.

Ao ler os textos presentes no site do projeto ESP a respeito de Paulo Freire, observase o comentário frequente de que esse faria exatamente aquilo que criticava: uma educação bancária. Ou seja, apresentaria ao aluno uma visão de mundo única que deveria ser aceita. Caso fosse questionado, o professor freireano reiteraria a sua opinião, sem apresentar aos alunos outros pontos de vista possíveis. Esses críticos acusam Paulo Freire de não ser tão neutro quanto supostamente diria ser, utilizando um ideal que Ihes é caro para julgar um pensador que nunca se propôs a ser neutro.

De fato, Paulo Freire sempre afirmou que educar é um ato político, onde não cabe neutralidade. Além de ter escrito um livro sobre isso -Ideologia e educação: reflexões sobre a não neutralidade da educação (Freire, 1981)-, várias passagens de suas obras atestam essa ideia, fundamental para o seu modo de pensar a educação: «não existe imparcialidade. Todos são orientados por uma base ideológica. A questão é: sua base ideológica é inclusiva ou excludente?» (2005, p. 27).

Que é mesmo a minha neutralidade senão a maneira cômoda, talvez, mas hipócrita, de esconder minha opção ou meu medo de acusar a injustiça? Lavar as mãos em face da opressão é reforçar o poder do opressor, é optar por ele. (Freire, 1996, p. 109)

A neutralidade frente ao mundo, frente ao histórico, frente aos valores, reflete apenas o medo que se tem de revelar o compromisso. Este medo quase sempre resulta de um 'compromisso' contra os homens, contra sua humanização, por parte dos que se dizem neutros. Estão comprometidos consigo mesmos, com seus interesses ou com os interesses dos grupos aos quais pertencem. E como este não é um compromisso verdadeiro, assumem a neutralidade impossível. (Freire, 1981, p. 19)

Assim, ao contrário de uma suposta neutralidade, que mascara o caráter social e histórico da produção de conhecimento, Freire defende o compromisso explícito com a

(3) Quando não houver outra referência, as informações sobre o movimento Escola sem Partido foram retiradas do seu site: https://www.escolasempartido.org/ [aceso 02/04/2021]. 
transformação de uma sociedade colonizada e marcada pela dialética perversa oprimido-opressor. Valoriza-se, também, o saber popular, os conhecimentos tradicionais que o aluno traz para o contexto escolar, que não coadunam com a concepção de neutralidade científica estabelecida. Ainda, o que se esconde atrás dessa pretensa neutralidade é um compromisso consigo próprio e com os grupos aos quais pertencem os partidários do movimento conservador.

Fica claro como o projeto ESP, que se coloca como contrário a qualquer ideologia na educação, é, em si mesmo, profundamente ideológico. A contundência retórica revela argumentos vazios que apenas escamoteiam o objetivo de formar um contingente de cidadãos trabalhadores alienados. Chama-se a atenção inclusive para o fato de que o grande alvo da ESP é a escola pública, ao passo que as escolas privadas brasileiras, onde estuda a elite, não estão renunciando a uma educação reflexiva, ainda que em prol da manutenção do status quo (Bittencourt, 2017).

Claro está que questões partidárias não devem ser tratadas no âmbito da práxis pedagógica. Entretanto, isso não deve ser entendido como a anulação de toda e qualquer reflexão política, até porque educar é sempre um ato político, conforme nos afirma Paulo Freire. Observa-se, portanto, uma confusão -certamente não impensada- entre política e partidos, decerto a fim de retirar do âmbito educacional qualquer análise de fenômenos da realidade e do estar concreto no mundo por parte dos alunos.

Certos temas têm sido vistos como polêmicos por representar um convite à reflexão sobre as frágeis sustentações das relações de opressão na cultura. Várias têm sido, por exemplo, as denúncias a professores considerados doutrinadores e esquerdistas. $\mathrm{O}$ site do movimento ESP reserva uma sessão especial para as explicações sobre como fazer uma denúncia contra professores. Na esteira do movimento, uma das mais recentes ideias do governo brasileiro é estabelecer um canal oficial de denúncias de pais a professores que representem um risco à moralidade de seus filhos.

É importante deixar claro aqui que a não neutralidade, ou seja, a tomada de posição, não significa a imposição de uma forma de pensar única. Trata-se, antes, do incentivo a uma reflexão crítica que conduza à conscientização por parte do estudante. $\mathrm{O}$ pensamento crítico deve ser, necessariamente, aberto. Se há uma modalidade de pensamento único em Paulo Freire, esse é o crítico, que, por definição, não é único.

É patente, portanto, a forma alienante que toma o projeto ESP, ao propor um formato rígido de educação, que não permite o pensamento crítico ou qualquer tipo de questionamento. $O$ modelo de educação caro a esse movimento pretende forjar um pensamento rígido e dogmático incapaz de permitir escolhas. A evitação do debate revela um silenciamento de toda e qualquer crítica, o que tece as bases do autoritarismo e dogmatismo. Não deixa de ser curiosa a disseminação dessas ideias em tempos em que se vê uma abundância de informações à disposição na internet. Fenômenos como esse, no entanto, que se somam ao das fake news, mostram que a única forma de controlar a verdade é alienar o aluno, o que revela um processo subjacente de colonização do ser e das mentalidades.

De acordo com Vigotski (2000), o que nos diferencia dos outros animais é justamente a capacidade de criação. Os seres humanos são dotados de um psiquismo que engloba afeto e criação: a consciência humana é capaz de reproduzir e criar, ao passo que outros animais só reproduzem por condicionamento. Ora, se se retira essa capacidade 
de criação do humano, se a escola retira do aluno a sua criatividade, ela está desumanizando-o, alienando estudantes de sua condição de humanos.

Nesse sentido, lembramo-nos de Simón Rodríguez com sua defesa inveterada da criatividade e inovação como única via possível da educação na América Latina. $E$, na mesma linha, Paulo Freire: «A educação é um ato de amor, por isso um ato de coragem. Não pode temer o debate. A análise da realidade não pode fugir à discussão criadora, sob pena de ser uma farsa» (Freire, 2006, p. 104).

\section{Pedagogia da esperança}

Para Freire, a educação é, em primeiro lugar, comunicação, diálogo entre pares que se encontram. Não é apenas uma busca por consenso, mas, também, uma ação estratégica que visa a um fim, qual seja, o de uma leitura crítica do mundo que se materialize na potência da transformação das relações de opressão existentes. É nesse sentido que devemos entender a Pedagogia da Libertação. Essa se baseia em uma ética do respeito ao outro, da consideração desse como um sujeito e na valorização do saber desse outro, que deixa de ser taxado de inferior e desvalorizado.

Esses processos, como vimos, visam fazer frente ao epistemicídio promovido pela colonialidade do ser e das mentalidades. Na América Latina, a educação dialógica é condição de possibilidade da tomada de consciência que permitirá superar a contradição da relação opressor-oprimido. A instauração desse diálogo entre membros de uma sociedade só é possível a partir da constituição de subjetividades críticas e autônomas nos oprimidos.

A fim de que se desconstrua o fatalismo associado à condição de oprimido, é imprescindível uma educação libertadora que mostre os meandros da mitologia da estrutura opressora - o que, poderíamos acrescentar, pressupõe igualmente a perda de legitimidade da mitologia do eurocentrismo. Isso só é possível com a problematização e o questionamento do contexto social em que se vive, que são ideologicamente tidos como naturais e necessários, bem como a compreensão dos mitos que agem no sentido dessa naturalização. Dessa forma, ao entender como essa estrutura opressora se sustenta, é possível ao educando se situar no interior dessa arquitetura, saindo, portanto, de seu lugar de passividade.

Em sua obra Pedagogia da Esperança (1992), Freire retoma, 25 anos depois, a obra Pedagogia do Oprimido, não para repeti-la, mas para falar sobre a sua repercussão e, também, para avançar com suas ideias. Assim, como faz Paulo Freire, nos perguntamos por que falar em Pedagogia da Esperança em um contexto tão «sem esperança», como o que se vive no Brasil no ano de 2019. A esperança de que se fala aqui não é a do verbo esperar, que remete a comodismo e passividade. Trata-se, antes, do verbo esperançar, que remete à ação crítica, à tomada de consciência e à práxis. «Enquanto necessidade ontológica a esperança precisa da prática para tornar-se concretude histórica» (p. 5).

Nesse ponto, a educação tem um papel fundamental: uma educação verdadeiramente popular, que aja no sentido de possibilitar que os estudantes passem de uma consciência ingênua para uma consciência crítica. É nesse sentido que Paulo Freire afirma que a educação sozinha não transforma o mundo, mas qualquer transformação substancial não será possível se não passar por ela, ou seja, se não implicar uma mudança radical na educação. 
Percebemos, assim, por um lado, a atualidade do pensamento de Paulo Freire, uma vez que o educador brasileiro trata de um processo que não é recente, mas, antes, remonta à própria história de colonização do continente latino-americano e à consolidação do capitalismo. Por outro lado, é possível igualmente notar a ameaça que ele representa. A manutenção do estado de colonialidade do ser e das mentalidades, cotidianamente reatualizada nos pormenores da vida nas nações do Sul global, é explicitada em um movimento como o da ESP, destacado neste texto. A esperança de viver em um mundo mais igualitário e menos opressor, de que nos fala Freire, pressupõe, portanto, um processo permanente de conscientização e libertação, no qual o diálogo e o pensamento crítico são peças fundamentais.

\section{Considerações Finais}

Falar da América Latina é falar da dualidade constante entre unidade e diferença, identidade e alteridade, modernidade e atraso, riqueza e expropriação, dentre outros pares de opostos que traduzem a tensão vivenciada historicamente no continente. Subjugada por um ferrenho processo de colonização que, mais que suas terras, atingiu mente e subjetividade de seus povos, vemos algumas tentativas de fazer frente à estrutura hegemônica: Simón Bolívar e sua busca por libertar e unificar a chamada Pátria Grande, Luís Inácio Lula da Silva e suas iniciativas de estabelecer um diálogo latino-americano autônomo, Simón Rodríguez e sua defesa por uma educação criativa e para todos e Paulo Freire, com sua proposta de educação que pretende superar a dialética oprimidoopressor.

Muitos outros nomes poderiam ser citados, inclusive de mulheres, que, como o próprio Paulo Freire reconheceu em seu livro Pedagogia da Esperança (1992), sofrem uma dupla opressão, até mesmo dentro dos movimentos de libertação. A construção histórica do lugar da mulher é, aliás, o que o combate à assim chamada ideologia de gênero pelo movimento ESP visa negar. Tratar desse tema, tão ou mais importante do que os abordados aqui, demandaria, entretanto, um novo texto.

A nossa intenção com este trabalho foi mostrar como movimentos que se apresentam como inovadores, como o ESP, se inserem em um esforço histórico de epistemicídio e de colonização de mentalidades, que servem à tentativa de manter, a qualquer custo, o status quo de uma nação colonizada. Não é por acaso que o atual governo brasileiro elege como seu principal parceiro nas relações internacionais justamente os EUA. Assim, uma elite local, em sua tentativa de se fazer cópia das nações dominantes no cenário global, conduz um programa que visa cessar qualquer possibilidade de discussão e questionamento da realidade.

Retomamos, assim, o pensamento de Paulo Freire em Pedagogia do Oprimido (2005) que alerta que, se a educação não for libertadora, o sonho do oprimido é se tornar opressor. Essa frase lança luz para a compreensão da história latino-americana e, no contexto brasileiro em 2021, mostra-se mais atual do que nunca.

\section{Referências}

Althusser, L. (1985) Aparelhos ideológicos de Estado. Rio de Janeiro, Graal.

Anderson, B. (2008) Comunidades Imaginadas. São Paulo, Companhia das Letras. 
Ardao, A. (1980) Génesis de la idea y el nombre de América Latina. Caracas, Centro de Estudios Latinoamericanos Rómulo Gallegos.

Bittencourt, R. N. (2017) «A impossível neutralidade discursiva na práxis educacional e a improbidade ideológica da Escola sem Partido». Revista Espaço Acadêmico, XVI, 191, pp. 117-133.

Canclini, N. G. (2008) Latino-americanos à procura de um lugar neste século. São Paulo, Editora lluminuras.

Castro-Gómez, S. (2000) «Ciencias sociales, violencia epistémica y el problema de la 'invención del otro'», em E. Lander (Org.), La colonialidad del saber: eurocentrismo y ciencias sociales. Buenos Aires, Clacso, pp. 169-186.

Díaz-Genis, A. (2004) La construccion de la identidad en América Latina. Montevidéu, Editorial Nordan-Comunidad.

Donghi, T. H. (1975) História da América Latina. São Paulo, Ed. Paz e Terra.

Dussel, E. (1994) 1492. El encubrimiento del Otro. Hacia el origen del «mito de la Modernidad». La Paz, Bolivia, Plural editores.

Dussel, E. (2000) «Europa, modernidad y eurocentrismo», em E. Lander. (Ed.), La colonialidad del saber: eurocentrismo y ciencias sociales. Perspectivas Latinoamericanas. Buenos Aires, Clacso, pp. 53-79.

Escobar, A. (2007) La invención del Tercer Mundo: Construcción y deconstrucción del desarrollo. Caracas, Fundación Editorial El perro y la rana.

Fausto, B. (2008) História do Brasil. São Paulo, EDUSP.

Freire, P. (1981) Ideologia e educação: reflexões sobre a não neutralidade da educação. Rio de Janeiro, Paz e Terra.

Freire, P. (1981) Educação e Mudança. Rio de Janeiro, Paz e Terra.

Freire, P. (1992) Pedagogia da Esperança: reencontro com a Pedagogia do Oprimido. Rio de Janeiro, Paz e Terra.

Freire, P. (1996) Pedagogia da Autonomia: saberes necessários à prática educativa. São Paulo, Paz e Terra.

Freire, P. (2005) Pedagogia do Oprimido. Petrópolis, Vozes.

Freire, P. (2006) Educação como prática de liberdade. Rio de Janeiro, Paz e Terra.

Kohan, W. (2015) O mestre inventor. Relatos de um viajante educador. Belo Horizonte, Autêntica Editora.

Madeira, M. A.; Veloso, M. (1999) Leituras Brasileiras: Itinerários no pensamento social e na literatura. São Paulo, Paz e Terra.

Martin-Baró, I. (2009) «Desafios e perspectivas da psicologia latino-americana», em R. S. L. Guzzo e Lacerda Jr., F. (eds.), Psicologia Social para a América Latina. Campinas, Editora Alínea, pp. 199-219.

Mignolo, W. D. (2000) «La colonialidad a lo largo y a lo ancho: el hemisferio occidental en el horizonte colonial de la modernidade», em E. Lander (ed.), La colonialidad del saber: eurocentrismo y ciencias sociales. Buenos Aires, Clacso, pp. 79-106

Mignolo, W. D. (2005) The idea of Latin America. New York, John Wiley and Sons.

Penna, C. (2014) «Paulo Freire no pensamento decolonial: um olhar pedagógico sobre a teoria pós-colonial latino-americana». Revista de Estudos e Pesquisas sobre as Américas, 8 (2), pp. 181-199. 
Quijano, A. (2000) «Colonialidad del poder, eurocentrismo y América Latina». Em E. Lander (Ed.), La colonialidad del saber: eurocentrismo y ciencias sociales. Perspectivas Latinoamericanas. Buenos Aires, Clacso, pp. 153-189.

Ramos, M. S.; Santoro, A. C. dos S. (2017) «Pensamento freireano em tempos de escola sem partido». Inter-Ação, 42(1), pp. 140-158.

Retamar, F. R. (1971) Calibán: apuntes sobre la cultura em nuestra América. México, Diógenes.

Rodó, J. E. (2006) Ariel. Madrid, Mestas Ediciones.

Rodríguez, Lidia M.; Marín, Carlos; Moreno, Silvia M.; Rubano, María del C. (2007) «Paulo Freire: una pedagogía desde América Latina». Ciencia, Docencia y Tecnología. XVIII (34), pp. 129-171.

Santos, B. S. (2007) Renovar a teoria crítica e reinventar a emancipação social. São Paulo, Boitempo.

Tavolaro, S. B. F. (2009) «América Latina, variável independente? Para uma crítica ao binômio centro-periferia». Teoria \& Pesquisa: Revista de Ciências Sociais, 18, pp. 85118.

Vygotsky, L. S. (2000) Obras Escogidas. Madrid, Visor, vol. III.

Zea, L. (1976) El pensamiento latinoamericano. Barcelona, Ariel. 


\section{El que espanta a Paulo Freire: educació alliberadora a Amèrica Llatina avui}

Resum: A partir de l'anàlisi del cartell contra Paulo Freire, en una manifestació a favor de la destitució de la presidenta brasilera Dilma Roussef, aquest article pretén explicar el rebuig a aquest educador i a la seva proposta pedagògica. Sembla una iniciativa nova però no deixa de ser un retorn a vells problemes d'Amèrica Llatina explicitats pels estudis decolonials a la regió. Obres com les de Paulo Freire són revolucionàries al proposar una educació popular orientada a la transformació social. No és una tècnica, sinó una postura de respecte, solidaritat i reconeixement en l'altre d'allò que no coneixem. El moviment Escola sem Partido, I'objectiu del qual és acabar amb el suposat adoctrinament d'esquerres a les escoles, vigila el mestre i té Paulo Freire com el principal focus. Aquest article aborda, doncs, el caràcter ideològic i reforçador del status quo que defensa aquesta proposta.

Paraules clau: Amèrica Llatina, estudis decolonials, Paulo Freire, educació.

\section{Ce qui fait peur chez Paulo Freire : éducation libératrice en Amérique latine aujourd'hui}

Résumé: À partir de l'analyse de l'affiche contre Paulo Freire lors d'une manifestation en faveur de la destitution de la présidente brésilienne de l'époque, Dilma Roussef, l'article vise à mettre la lumière sur le rejet de cet éducateur et de sa proposition pédagogique, qui sous des apparences de nouveauté, ne fait que remettre en question, d'un autre point de vue, d'anciens problèmes de l'Amérique latine, rendus explicites par les études décoloniales menées dans la région. Des œuvres comme celle de Paulo Freire, qui proposent une éducation populaire visant à la transformation sociale, sont révolutionnaires. Ce n'est pas une technique, mais une position de respect, de solidarité et de reconnaissance dans l'autre de ce que nous ne savons pas. Le mouvement «École sans parti », qui vise à mettre fin à un prétendu endoctrinement à gauche dans les écoles, supervisant l'enseignant, a pris Paulo Freire comme cible privilégiée. Ce document aborde le caractère idéologique et renforçant du statu quo que cette proposition défend.

Mots-clés: Amérique Latine, études décoloniales, Paulo Freire, éducation

\section{Who's afraid of Paulo Freire: liberating education in Latin America today}

Abstract: From the analysis of a poster criticizing Paulo Freire in a pro-impeachment demonstration of then Brazilian President Dilma Roussef, the article aims to show that the rejection of this educator and his pedagogical proposals is not something new but is merely a new guise for old issues in Latin America, made explicit by the decolonial studies in the region. Works such as Paulo Freire's are revolutionary in proposing a popular education aimed at social transformation. It is not a technique, but a position of respect, solidarity, and recognition in the other of what we do not know ourselves. The movement School without Party, which aims to end a supposed left-wing indoctrination in schools, by putting teachers under surveillance, has Paulo Freire as its major target. This paper approaches the ideology and reinforcement of the status quo that this proposal defends.

Keywords: Latin America, decolonial studies, Paulo Freire, education. 